\title{
Pessoa, utopia e formação de professores*
}

\section{Individual, utopia and teachers formation}

\author{
Blanca Beatriz Díaz Alva**
}

\begin{abstract}
RESUMO
Nesse artigo são analisados, a partir da perspectiva da desumanização do ser humano pela sociedade tecnológica, o homem-pessoa, as relações entre pessoa e sociedade e o homem como ser utópico, a fim de promover uma reformulação da formação de professores para uma prática reflexiva, crítica e ética, no intuito de recuperar o ser do homem no processo educacional. Palavras-chaves: Homem-pessoa, pessoa e sociedade, utopia, formação de professores.
\end{abstract}

\begin{abstract}
In this paper, human being-person, the person-society relationships, and the man as an utopic being are analysed, according to the perspective of the human being losses of humanization for the technological society. It aims to discuss a reformulation of teacher's professional preparation towards a reflexive, critical and ethical practice, whose purpose is to recover the human condition in the educational process.

Key-words: Man-person, person-society, relationship, utopy, teacher'formation.

* Este trabalho foi apresentado como comunicação (em espanhol) no CONGRESO SOBRE EDUCACIÓN, FORMACIÓN Y DESARROLLO DA REDFORD (Rede Educação, Formação e Desenvolvimento de Universidades Européias e Latino-americanas), 5, 2001, Havana, Cuba.

** Professora Visitante no Departamento de Teoria e Prática de Ensino - DTPEN e no Curso de Pós-Graduação em Educação da Universidade Federal do Paraná. beadoce @ terra.com.br.
\end{abstract}




\section{Introdução}

Este artigo apresenta algumas das reflexões feitas no desenvolvimento de atividades relacionadas ao projeto de pesquisa intitulado "Ética e cultura na formação de educadores", desenvolvido na linha de pesquisa Saberes, cultura e práticas escolares no Programa de Pós-Graduação em Educação da Universidade Federal do Paraná.

A pergunta que orientou a elaboração do projeto, e que pretendemos discutir, aqui, é a seguinte: como formar professores numa sociedade pósmoderna? Certamente é um desafio. Nossa sociedade pós-moderna é vista como uma sociedade em crise, essencialmente em crise de valores, confundida e desapontada pela sociedade chamada de moderna, que foi conseqüência da Revolução Industrial. Nesse artigo, queremos ressaltar e fundamentar a importância de reformular a formação de professores para uma prática reflexiva, para a participação crítica e para o questionamento ético, no intento de recuperação do fator humano nessa sociedade tecnológica e burocrática, tecnologia e burocracia que também afetam o pensamento universitário.

Se, por um lado, é necessário um estudo das características mais relevantes da sociedade tecnológica e seus efeitos sobre o ser humano, por outro lado é imprescindível, com o intuito de abordar a essencialidade da realidade humana para apontar os elementos que a caracterizam, definir o que é o homem, delimitar quem é o ser humano. Só assim poderíamos apontar a desumanização da sociedade tecnológica.

Queremos refletir, a partir das próprias condições da existência humana, sobre o homem-pessoa, sobre pessoa e sociedade, e sobre o homem como ser utópico, a fim de estabelecer um ponto de partida e um ponto de chegada para o processo educativo da formação de professores, reconhecendo que uma sociedade baseada na racionalidade da técnica não pode fazer justiça à complexa realidade humana.

A civilização contemporânea, hoje talvez mais do que antes, apresenta-se em crise, crise de valores e crise de "modelos" para os nossos jovens. Nessa sociedade predomina a violência, transformando todo esse potencial humano de juventude: onde deveriam predominar o amor, a amizade e a confiança, há relações de ódio, antagonismo e temor. O progressivo avanço no campo material em descompasso com o domínio da moral, ameaça cada vez mais o homem.

MARCEL (1967) distingue, numa sociedade tecnológica, o "ser" do "ter", fazendo uma dura condenação à técnica como responsável pela desumanização 
do homem contemporâneo, já que numa sociedade tecnológica e industrial tudo se reduz àquilo que se tem. Nesse plano do "ter" e, por conseguinte, da objetividade, da técnica, do fazer, encontra-se a alienação, a angústia, o desespero. Nesse aspecto, o homem é degradado a simples objeto, isto é, o homem quanto mais possui tanto mais é possuído pelas coisas. Escravizado pelos objetos, o homem deixa de ser ele próprio a tal ponto que a fórmula filosófica que o orienta, na modernidade, é a de que o homem não vale pelo que é, mas pelo que produz, e por conseguinte pelo que tem.

Esses conceitos, do "ser" e do "ter", têm sido tratados também por Erich Frömm que assim se manifesta: “... na medida que haja satisfação das necessidades básicas materiais, a continuidade predominante do modo de vida "Ter", bloqueia a realização do modo de vida "Ser". E a realização do modo de vida "Ser" é o que caracteriza realmente o fenômeno humano e que permite sua ampla realização" (FröMm, 1987, p. 26).

Assim, podemos resgatar a preocupação por um humanismo, por recuperar a humanidade do homem numa sociedade na qual tudo deve ser tratado científica e tecnicamente.

Compreendemos, então, que nesta redução da realidade, dada pela sociedade tecnológica, há um lugar muito pequeno para conceitos como "dignidade humana", "justiça", "liberdade". Para a ciência, esses conceitos soam como palavras sem significado por que pertencem a uma linguagem que ela ignora quase que completamente (NogARE, 1985).

Com essa reflexão, vamos nos introduzir no campo educativo, pois, numa perspectiva humanista, a educação, e especialmente a formação de professores, é um empreendimento eminentemente humano, já que visa a realização do homem, e no caso do professor, a realização do educador, que é o que justifica sua existência.

\section{O homem pessoa}

Benjamin Franklin definiu o homem como Homo faber, isto é, como animal técnico, como fabricante de ferramentas. Essas invenções, por força das quais o homem primitivo tornou-se tão predominante, constituem um resultado direto do desenvolvimento de seus poderes de observação, memória, curiosidade e razão (NogARE, 1985). 
Assim, a técnica em si está muito longe de ser anti-humana. Aliás, ela confunde-se com a própria natureza, constituindo-se no principal recurso de sobrevivência e desenvolvimento do homem; a técnica não seria nem boa nem má, sua qualificação ética dependeria do uso que dela faça o homem.

Também SAVIani (1983) assinala que o homem, pelo fato de se apresentar como um corpo, e por isso existindo num meio que se define pelas coordenadas de espaço e tempo, está condicionado ao meio e determinado por ele em todas as suas manifestações. Seu caráter de dependência verifica-se primeiro em relação à natureza, isto é, a tudo aquilo que existe independentemente de sua ação, e também ao meio cultural que se lhe impõe inevitavelmente.

Configuramos então, o homem como um ser situado, o que significa que desde que nascemos, além de termos uma localização geográfica mais ou menos favorável, também nos deparamos com uma época de contornos históricos precisos marcada pelo peso de uma tradição mais ou menos longa, com uma língua já estruturada, com costumes e crenças definidas e numa sociedade com instituições próprias, uma vida econômica peculiar e uma forma de governo própria.

No entanto, o homem, por ter consciência, não é totalmente determinado por seus instintos. Contrariamente aos animais, o homem carece de um determinismo instintivo, pois na medida em que se ascende na evolução animal, tal determinismo alcança, no homem, seu ponto mais baixo. Pelo fato de ser biologicamente mais fraco que os animais e mais indefeso face à natureza, encontra precisamente nessa fragilidade biológica sua força, já que esta é a causa primordial do desenvolvimento de suas qualidades humanas (FRömM, 1981).

Contrariamente aos animais, o homem, não determinado por seus instintos, é capaz de tomar decisões. O homem é o ser que arrisca e que busca continuamente através da esperança.

Pela sua consciência racional, reflexiva e apreciativa, o homem transcende a natureza. Numa perspectiva personalista, a grandeza humana reside no fato de que o homem, imerso na natureza, a transcende. Trata-se de uma transcendência da pessoa que não é um "além" metafísico, porém um movimento de superação do individualismo e do egoísmo, uma tentativa de dar origem a uma nova humanidade libertada das misérias individuais e das desigualdades sociais, em condições de conseguir a perfeita felicidade humana.

Um dos sinais da transcendência é a liberdade. Assim, uma das características mais importantes do ser humano é a de ser livre.

Um outro aspecto que devemos considerar é que não se tem liberdade unicamente pelo fato de exercer a espontaneidade; o homem torna-se livre na 
medida em que usa essa espontaneidade para se libertar. Portanto, a liberdade da pessoa humana caracteriza-se por duas grandes dimensões intimamente unidas e mutuamente constituídas: "liberdade é autonomia na medida em que é libertação dos dados opressivos de sua situação", afirma SEvERINo (1983, p. 70). Ainda, atuando o homem como ser livre, é fonte contínua de criatividade e jamais o homem-pessoa poderá ser substituído pela técnica.

\section{Pessoa e sociedade}

A palavra "pessoa" trata de designar uma característica muito peculiar do indivíduo da espécie humana. Segundo Boécio, a palavra "pessoa" procede de personna, no sentido de máscara, a máscara de que se serviam os atores nas comédias e tragédias antigas; e assim como essas máscaras representavam os heróis cujos papéis os atores desempenhavam, chegamos também a chamar de "pessoa" os demais homens que se distinguem por uma marca, por um aspecto particular, atuando como personagens no cenário do mundo (MARITAIN, 1949).

Tristão de Athayde dizia em suas conferências que o indivíduo é um débito do homem para a comunidade; enquanto que a pessoa é um débito da comunidade para com o homem. O indivíduo é sempre devedor (Morais, 1991). A pessoa é credora de direitos específicos (MARItAin, 1962).

Ludwig Feuerbach já insistia na necessidade de uma experiência do "tu" para ter consciência de nós mesmos enquanto "eu", manifestando que: "O indivíduo em si, não possui o ser do homem em si, nem enquanto ser moral, nem enquanto ser pensante. O ser do homem encontra-se só em comunidade, na unidade do homem com o homem, unidade que fundamenta-se só na realidade da diferença entre Eu e Tu" (apud BubER, 1977, p. 15).

É de Feuerbach que Buber recebe impulso decisivo para a construção de sua filosofía do diálogo, admitindo que "a pessoa aparece no momento em que entra em relação com outras pessoas" (BUBER, 1977).

Se recordarmos a frase orteguiana "eu sou eu e minha circunstância", podemos admitir que sem mundo exterior não há mundo interior, já que tudo o que sentimos e sabemos nos vem da convivência com o mundo e do meio humano. "Circunstância" é tudo o que nos rodeia, o mundo físico, social, meu corpo, minha psiquê, ainda que estes últimos sejam também partes do "eu". 
Já Maritain (1949) escreve que a pessoa é um todo, porém não um todo fechado, é um todo aberto. A pessoa, por ser um ser inacabado, procura incesantemente ser mais, transcender; procura na sociedade sua complementação e compreende que nessa busca não está só, que há outras pessoas iguais a ela que buscam também ser mais. E assim é que, em comunicação com outras consciências, "afirma-se - diz Blondel -, desenvolve-se, adquire seu valor, em oposição, colaboração e dedicação, quer dizer, em relação com outras existências" (apud ETCHEVERRY, 1964, p. 281). Eis que encontramos o efeito construtivo da circunstância sobre o "eu", razão pela qual um homem só pode ser compreendido à luz de seu contexto sociocultural e histórico.

A sociedade surge, então, proporcionando à pessoa "as condições de existência e de desenvolvimento de que tem precisamente necessidade. Não é totalmente só que pode chegar a sua plenitude; é como recebendo da sociedade bens essenciais" (MARITAIN, 1962).

Quando MARITAIN (1962) menciona bens essenciais não se refere apenas aos bens materiais, senão antes de tudo à ajuda que ele necessita para fazer "obra de razão e de virtude", que corresponde ao caráter específico do ser humano. E para chegar a um certo grau de elevação no conhecimento, como de perfeição na vida moral, o homem tem necessidade de uma educação. Desta maneira, o ser humano realiza-se em sociedade sem perder sua autonomia e sem deixar de ser fim em si mesmo.

Não há liberdade senão na comunidade. Por isso, não devemos conceber como prioritária a relação dos indivíduos com o Estado, mas sim sua relação com os núcleos sociais mais naturais e imediatos em que o homem se integra e onde desenvolve suas forças criadoras e sociais como a família, a escola, a comunidade de vizinhos, a universidade.

Essas instituições são o lugar de começar a estabelecer esse encontro iluminado entre duas existências, entre duas pessoas, mediante a estima, a cordialidade, a confiança, a sinceridade, o respeito, onde tem de surgir a própria consciência e valorização pessoal. 


\section{O homem, ser utópico}

Pelo fato de ter consciência e conceber-se como um ser inacabado, necessitado e imperfeito, consciente de que ainda não é o que poderia ser, o homem vive inquieto e em contínua busca: de ser mais, de conseguir a felicidade, de obter bem-estar. Nessa busca, longe de se mostrar como ser passivo, é crítico por que recusa o mundo em que vive por um mundo melhor, instalando-se nele uma atitude esperançosa cheia de fé. VERSIANI (1973, p. 6) afirma que "ser homem quer dizer na realidade ter utopia".

A palavra utopia foi cunhada por Thomas Morus em 1516, sendo formada pela partícula negativa "u" (não) e por "topos" (lugar, região, país). Assim, "utopia” significa "não região", "não lugar". No entanto, também pode significar um lugar imaginável, um estado de ser, um modelo a conquistar.

Essa atitude sempre presente no homem, de construir uma utopia, significa repensar o horizonte de vida em que se viveu até então, significa recusar a "topia", isto é, o quadro de referência recebido culturalmente, ou mesmo adotado livremente em um determinado momento da existência (Versiani, 1973).

As utopias surgem nos momentos de transição e de crise, estes seus momentos áureos, pois têm como principal característica ser um ideal dinâmico capaz de mobilizar as potencialidades mais ricas da existência humana. E se a utopia não é o não-lugar nem o não-tempo das concepções caseiras, é a maior possibilidade da existência, é tensão constante, é a ânsia de outras dimensões, é negação ao conformismo. Sem este elemento utópico, o mundo do homem não haveria emergido da barbárie e do instinto. A utopia é um fim, uma meta que pode ser o reino de Deus, a sociedade sem classes, o mundo justo, aspirações próprias da condição de ser homem (CAPELLA, 1989).

Ernest Bloch (apud Morais, 1988) considera que a raiz de toda utopia é o "ainda não", isto é, o espaço de possibilidades em que se encontra constantemente situado o ser do homem e do mundo. Para explicar a utopia, este autor parte da análise da humanidade do homem, vendo no fato comum da necessidade de ter fome as características próprias do fenômeno utópico. Demonstra que esse fato, o de ter fome, não significa apenas um fato socioeconômico universal, mas que tem uma significação muito mais profunda na condição humana. Quando o ser humano, explica Bloch, toma consciência de que tem fome, não fica tranqüilo, lança-se à busca do alimento, pois, o fato de ter fome desperta a consciência e esta é o primeiro sinal que nos faz ver que somos seres necessitados, precisando sair em busca de meios possíveis que possam satisfazer essa necessidade. 
Tomar consciência da carência ou necessidade e da possibilidade de um possível, configuram os passos do princípio da esperança. Assim, "o homem estrutura-se como um ser carente, imperfeito e insatisfeito" (FURTER, 1974, p. 80).

A consciência de ter fome nos leva também à constatação de que não se trata apenas de uma sensação individual e interna, senão que nos conduz a um projeto em que o "outro" aparece como uma ameaça pelo mesmo fato de também ter fome. Porém, é justamente pela solidariedade que o "outro", longe de ser uma ameaça, surge como companheiro para partir junto conosco na busca do possível. Assim, Bloch (apud Morais, 1988) nos faz ver, através dessa necessidade básica, que alcançamos os primeiros esboços de uma humanidade que se comunica em uma mesma ansiedade e em uma procura comum pelo essencial.

A função de inconformidade da utopia nos conduz a uma atitude crítica da realidade, não no sentido de um pensamento dirigido à análise do social, mas para um pensamento crítico que projeta, no sentido em que Paulo Freire utiliza esse termo quando diz: "Utopia é a dialectização dos atos de denunciar e anunciar, o ato de denunciar a estrutura desumanizante, de anunciar a estrutura humanizante. Por essa razão, a utopia é também um compromisso histórico" (FREIRE, 1980, p. 27).

Nessa atitude de crítica do atual, o pensamento utópico não cai no irreal, mas apóia-se nas tendências fundamentais do presente que têm suas raízes no passado para irromper no futuro e, assim, reconstruir o real. Essa mudança do passado pela reconstrução do real para um futuro melhor está marcada pelo surgimento e pela consolidação de um modelo que, por ser um plano humano, é suscetível de revisão. Nesse sentido, dizemos que o pensamento utópico propõe um instrumento prospectivo, isto é, que nos permite ver adiante, impedindo que nos contentemos apenas com a simples constatação científica do que existe, do que está: o real é muito maior do que aquilo que está presente, desta maneira a utopia nos obriga a explorar os possíveis concretos dos quais o real está prenhe (FURTER, 1974).

\section{Utopia e formação de professores}

Até aqui apresentamos o homem como pessoa e como ser social. Ele é um ser orientado utopicamente, antecipador de um futuro, com uma esperança inextinguível, que crê num mundo perfeito como uma meta da história e 
que ademais de imaginar mundos diferentes e melhores, atua mediante fatos concretos, fazendo uso de seu pensamento como instrumento fundamental para conhecer a realidade e enfrentá-la.

Se é essa a compreensão do que seja o homem, a utopia apresenta uma força de primeira ordem no contexto de uma educação mais humana; o que significa que a educação tem de estar adaptada ao fim que se persegue, permitindo ao homem chegar a ser sujeito, construir-se como pessoa, transformar o mundo, estabelecendo com os homens relações de reciprocidade, fazendo cultura e história.

Pensar em educação - assinala LoPEZ EsCALONA (1983) - supõe professar uma concepção de homem, propor fins e estudar os meios; supõe também planificá-la, administrá-la e organizá-la para determinados fins.

Em outras palavras, a educação requer uma filosofia subjacente para as diversas decisões relativas às ações e políticas educativas. Toda ação educativa tem de supor uma hierarquia de valores e uma posição a respeito do relacionamento entre as pessoas e grupos e também a respeito das inter-relações entre a instituição e a sociedade.

Dessa maneira, a educação para a mudança social requer, como condição prévia, a consideração de uma concepção antropológica humanista, pois a partir dela dar-se-á a modificação do homem em função do especificamente humano e não em função de interesses sociais que desconheçam ou esqueçam as dimensões essenciais do ser humano.

Sob essa perspectiva podemos conceber a educação como um processo e simultaneamente como um projeto, por que "a educação move-se com a história e move a história", e nesse sentido é um projeto histórico, que "é como se fosse oxigênio para o projeto pedagógico. Prescindir do projeto histórico ou subestimar seu significado provocaria uma asfixia dos propósitos educativos" (CAPELlA, 1988, p. 41). A educação, segundo Rezende (1979), é também um projeto cultural pelo qual um determinado grupo assimila e vive a imagem de homem veiculada por sua respectiva cultura.

Como nossa intenção é, aqui, refletir sobre a formação de professores através de uma perspectiva humana cabe ainda dizer que, nesse contexto de idéias, a educação constitui um movimento de construção de uma cultura alternativa que expressa a projeção de um homem novo e de uma sociedade distinta. Essa responsabilidade ultrapassa os limites da tradicional conservação, transmissão e difusão do saber, reivindicando o sentido da criticidade já que formula uma concepção educativa centrada na interrogação, na deliberação e na valorização da realidade histórica. Em palavras de FreIRE (1980), a educação crítica é o futuro revolucionário. Ela é profética e, como tal, porta- 
dora de esperança, e corresponde à natureza histórica do homem. Ela afirma que os homens são seres que se superam, que vão adiante e olham para o futuro.

Essa criticidade permite potencializar o caráter criador da educação. Não pode haver educação favorável à mudança independentemente do desenvolvimento de seu significado criador. Ela deve, em conseqüência, orientar-se para o desenvolvimento, para a descoberta e para a invenção, pois toda a dimensão crítica e criadora da educação configura o sistema de apoio para sua vinculação com o projeto histórico que se pretende.

O ensino superior para a formação de professores deve contar com profissionais competentes, pois lhes cabe justamente a função de formar os futuros educadores, os quais devem também ser competentes. Com sua atuação crítica, tais profissionais traçarão objetivos que indicarão o que não foi ainda alcançado, mas que o deve ser, isto é, assinalarão os pontos chaves da ação, sintetizando o esforço do homem em transformar o que deve ser em aquilo que é.

Quando pensamos em professores, ou melhor, educadores competentes, referimo-nos a homens de elite em sentido ético, segundo análise que Morais (1989) faz do termo "elite". Em sua análise, o mencionado autor afirma que o termo "elite" tem raízes muito antigas "quando lhe procuramos a pureza inicial. Raízes que se submergem no terreno muito diverso do das análises políticas e disputas de classe" (Morais, 1989, p. 51). Esse conceito grego traça o perfil do verdadeiro cidadão. Assim, o homem de elite, em sentido ético, é "aquele que não é egoísta a ponto de não se preocupar com os problemas de todos, a ponto de distanciar-se das vicissitudes e alegrias da polis" (Morais, 1989, p. 51)

O homem de elite, segundo o mesmo autor, é aquele homem distinto dos demais, e isto por ter conquistado a disposição real de autoconstruir-se, procurando e se esforçando em edificar solidamente sua personalidade em um processo de constante abertura para seu tempo e para com seu mundo, em um processo de relação tranqüila e serena para com todos. Não só para com os iguais senão também com os desiguais em termos de posição social.

Transferindo esse termo para o campo educativo, professores são homens de elite que se distinguem por não cometer erros deploráveis no dimensionamento humano, são aqueles educadores cujo amor próprio os levou a conhecer muito bem sua ciência e cuja percepção do outro como pessoa, os levou a jamais se fechar em narcisismos. E nisso radica o fato de estudar para ser mais e crescer como pessoa, ainda na contracorrente de um mundo cuja preocupação é ter mais técnicos (MoRAIs, 1989). 
Sendo esse o princípio da educação superior, o professor, como homem de elite, tem de ser um "revoltado", o que não significa ser um "ressentido". Homem de elite é o que se revolta em nome dos valores e contra tudo aquilo que diminui o ser humano de alguma forma.

"A consciência nasce da revolta", diz Camus (apud Morais, 1989) e Morais completa a frase assinalando que "é com a consciência desmistificada [que] nasce um homem de elite" (Morais, 1989, p. 54). Nesse sentido, toda ação educativa deve ser elitizante, o que permitirá uma sólida formação para a cidadania, e a educação superior deve sê-lo mais que nenhuma outra.

$\mathrm{Na}$ esperança encontraremos os elementos necessários para nos orientar em direção a um projeto educativo que, partindo de nossas raízes históricas, encaminhe-se para a recuperação do sujeito, pois o que assistimos em nossos dias é o colapso do sujeito como pessoa.

Situados no contexto de um humanismo personalista, concluímos que a educação é um processo liberador mediante o qual o homem deixa de ser só "paciente" para se transformar em "agente" de seu próprio destino, em virtude de sua capacidade transformadora. Dessa maneira, e considerando o ser humano inserido no mundo para com ele comungar e também transcendê-lo, a educação como verdadeira praxis exige reflexão do homem sobre o mundo para torná-lo melhor.

\section{REFERÊNCIAS}

BUBER, M. Eu e tu. São Paulo: Cortez e Moraes, 1977.

CAPELLA, J. La educación para la paz en la formulación de políticas educativas. In: KLAIBER, J. (Coord.). Violencia y crisis de valores en el Perú. Lima: Pontificia Universidad Católica del Perú, 1988.

. Responsabilidad de la educación en la construcción de una cultura de paz. In: MACGREGOR, F.; GONZALES, M. R.; CAPELLA, J. (Orgs.). Educación, futuro, cultura de paz. Lima: Pontificia Universidad Católica del Perú, 1989.

ETCHEVERRY, A. O conflicto atual do humanismo. Porto: Livraria Tavares Martins, 1964.

FREIRE, P. Conscientização. São Paulo: Moraes Ltda., 1980. 
FRÖMM, E. Ter ou ser? Rio de Janeiro: Guanabara, 1987. . A Revolução da esperança. Rio de Janeiro: Zahar, 1981. . Análise do homem. Rio de Janeiro: Guanabara, 1986.

FURTER, P. Dialética da esperança: uma interpretação do pensamento utópico de Ernest Bloch. Rio de Janeiro: Paz e Terra, 1974.

LOPEZ ESCALONA, S. Antropologia e educação. São Paulo: Paulinas, 1983.

MARCEL, G. Em busca de la verdad y de la justicia. Barcelona: Herder, 1967.

MARITAIN, J. La defensa de la persona humana. Madrid: Studium de Cultura, 1949. . A pessoa e o bem comum. Lisboa: Livraria Morais, 1962.

MORAIS, J. F. R. de. Filosofia da ciência e da tecnologia. Campinas: Papirus, 1988. . Cultura brasileira e educação. Campinas: Papirus, 1989. . Entrevista informal com a autora, 1991.

NOGARE, P. D. Humanismos e anti-humanismos. Petrópolis: Vozes, 1985.

REZENDE, A. Administrar é educar ou... deseducar. Revista Educação e Sociedade, São Paulo, n. 2, p. 25-35, jan. 1979.

SAVIANI, D. Educação do senso comum à consciência filosófica. São Paulo: Cortez e Autores Associados, 1983.

SEVERINO, A. Pessoa e existência. São Paulo: Cortez e Autores Associados, 1983.

VERSIANI, M. Atualidade do pensamento utópico. Revista de Cultura Vozes, v. 1, n. 117, p. 5-12, jan./fev. 1973. 